\title{
Managing Medical Requests From Family and Friends
}

\author{
Kelly A. Thibert, DO, Grant Family Medicine, ObioHealth \\ Michael E. Jobansen, MD, MS, Associate Editor \\ Ann Fam Med 2018;16(1):iii. https://doi.org/10.1370/afm.2195
}

The Annals of Family Medicine encourages readers to develop a learning community to improve health care and health through enhanced primary care. Participate by conducting a RADICAL journal club. RADICAL stands for Read, Ask, Discuss, Inquire, Collaborate, Act, and Learn. We encourage diverse participants to think critically about important issues affecting primary care and act on those discussions. ${ }^{1}$

\section{HOW IT WORKS}

In each issue, the Annals selects an article and provides discussion tips and questions. Take a RADICAL approach to these materials and post a summary of your conversation in our online discussion. (Open the article and click on "TRACK Discussion/ Submit a comment.") Discussion questions and information are online at: http://www.AnnFamMed.org/site/AJC/.

\section{CURRENT SELECTION}

Giroldi E, Freeth R, Hanssen M, Muris JWM, Kay M, Cals JWL. Family physicians managing medical requests from family and friends. Ann Fam Med. 2018;16(1):45-51.

\section{Discussion Tips}

This article explores the experiences of newer and more seasoned family physicians in managing medical requests from family and friends outside the clinical setting. Think about your time as a medical student, resident, and/or attending physician and recall your own lived experiences when a friend or family member asked for your expertise to help them medically. Consider if you would have handled those situations differently at various stages of your training.

\section{Discussion Questions}

- What question is asked by this study and why does it matter?

- How does this study advance beyond previous research and clinical practice on this topic?
- How strong is the study design for answering the question?

- What is a focus group? What are the strengths and weaknesses of focus groups?

- What is an inductive thematic analysis?

- To what degree can the findings be accounted for by:

- How physicians were selected or excluded?

- How the data were collected?

- How the findings were interpreted?

- The perspective or viewpoint of the analyst?

- What are the main study findings?

- Is there an ethical line physicians should not cross in treating nonpatients? Are there "grey areas" that are more acceptable?

- What similarities/differences are there between a nonpatient requesting an opinion from a physician compared to comparable requests of other professionals (ie, retirement planners, lawyers, etc)?

- What is your judgment about the transportability of the findings? How might the findings change across countries? Across specialties?

-What contextual factors are important for interpreting the findings?

- How might this study change your practice? Policy? Education? Research?

- Who are the constituencies for the study and how might they be engaged in interpreting or using the findings?

-What researchable questions remain?

\section{References}

1. Stange KC, Miller WL, McLellan LA, et al. Annals Journal Club: It's time to get RADICAL. Ann Fam Med. 2006;4(3):196-197. http:// annfammed.org/cgi/content/full/4/3/196. 